\title{
Evaluation of Dissolving Effect of Chloroform on Three Root Canal Sealers: An In Vitro Study
}

\author{
Azah Binti Zainal Abidin ${ }^{1}$, Azmiera Binti A. Rahman ${ }^{1}$, Dr Kyaw Mya Htun ${ }^{2}$,Dr Tin Maw ${ }^{3 *}$ \\ ${ }^{1}$ Students, Kuliyyah of Dentistry, IIUM \\ ${ }^{2}$ Lecturer, Restorative Dentistry Unit, Kuliyyah of Dentistry, IIUM \\ ${ }^{3}$ Lecturer, Dental Public Health Unit, Kuliyyah of Dentistry, IIUM \\ *E-mail: drtinmaw@iium.edu.my
}

\begin{abstract}
Objective: The purpose of this study was to evaluate and compare the dissolving effect of chloroform on AH 26 (resinbased root canal sealer), Endofill (zinc oxide eugenol-based root canal sealer) and Sealapax (calcium hydroxide-based root canal sealer). Many previous literatures have compared the solubility of several solvents towards gutta percha but very few on endodontic sealers.
\end{abstract}

Methods: The materials used in this experiment apart from the three endodontic sealers are 30 standardized stainlesssteel rings, microscopic glass slide, chloroform, acetone, and three decimal digital weighing scales. Thirty standardized stainless steel rings $8 \mathrm{~mm}$ in diameter and $3 \mathrm{~mm}$ in height were used for the preparation of sealer specimens and were randomly divided into three experimental groups of ten rings each. Each sealer was then mixed in accordance with the manufacturer's instructions and introduced into the stainless-steel rings and was weighed to obtain the initial weight. Each sealer was weighed again after immersion in chloroform. The amount of sealer lost was the difference between this measurement and the original weight of the sealer. The results were tabulated and analyzed using analysis of variance (ANOVA).

Results: The ANOVA test showed that there were significant differences existed between the groups. The post-hoc (Bonferroni) test showed that AH26 had significantly greater dissolution than Sealapex. However, there were no significant differences in dissolution between AH26 vs. Endofill and Sealapex vs. Endofill.

Conclusion: According to the methodology proposed and based on the results of this study, it may be concluded that AH26 presented the highest dissolution value.

Keywords: chloroform, dissolves, sealers

\section{Introduction}

Root canal therapy has been a predictable mean in preserving natural teeth. Root canal treatment is in need when the pulp gets infected and inflamed due to dental caries, placement of restorative materials or trauma to the teeth. Though the success of the root canal therapy is high, many teeth every year need to be retreated.

In certain areas of the United States, endodontists reported that $25 \%$ to $80 \%$ of their cases were retreatment cases. ${ }^{1}$ Endodontic retreatment requires finding all of the canals, removal of the present restorations (including core material and sealers), re-instrumentation of the canal and filling the canal with new materials and sealers.

During retreatment, a solvent can facilitate the removal of obturation material (i.e. gutta percha) by softening it. ${ }^{2}$
However, the remaining sealer used to fill the space between the gutta percha filling and dentinal tubule remain and its removal is essential to obtain a root canal free of debris and microorganisms which may be the primary cause of endodontic failure.

Fortunately, solvents used in removing gutta percha can also be used to dissolve sealers. The most commonly used solvent is chloroform because it acts very rapidly and is the most efficient in softening gutta-percha. ${ }^{3}$ However, the dissolving effect of chloroform is not the same towards all sealers. Many in vitro studies have demonstrated the dissolving effects of solvents towards gutta percha, but less towards the sealers. Furthermore, different sealers have different degrees of solubility in different solvents with varying different techniques (Grossman, 1978). Hence an experiment on evaluating the dissolving effect of chloroform needs to be carried out. 
This study aims to: 1) evaluate the dissolving effects of three endodontic sealers towards chloroform and 2) determine whether the solubility effects of chloroform are similar towards different types of root canal sealers. The word evaluation in this study entails any weight changes of the sealers before and after immersion inside the chloroform.

Hence, the bigger the weight changes of the sealer, the greater its dissolving capability towards the chloroform. Meanwhile the word dissolving refers to the ability for a given substance (the solute), which is the endodontic sealer, to be soluble in a solvent, in this case - chloroform.

In this in vitro study, three different types of root canal sealers were chosen; resin-based sealer (AH26, DeTrey), zinc oxide-based sealer (Endofill, ProduitsDentaires) and calcium hydroxide-based sealer (Sealapax,SybronEndo).

A resin based sealer was chosen as it is the latest and most widely used sealer. As for Endofill, it was chosen as it met most of the Grossman requirements of an endodontic sealer and as for Sealapex it was chosen as too little in vitro investigation was carried out in terms of its solubility.

This in vitro study clinically mimics the retreatment of endodontic fillings. Ratios of sealer and solvent used are identical.

\section{Methods}

The following sealers were used in this study: resin-based sealer (AH 26, DeTrey) zinc oxide based sealer (Endofill, Produits Dentaires) and calcium hydroxide based sealer (Sealapax, Sybron Endo). Eleven standardized stainless steel rings were prepared with measurements of $8 \mathrm{~mm}$ in diameter and $3 \mathrm{~mm}$ in height. Ten rings were used for each sealer and one ring was for the control. The control ring was weighed using three decimal places digital weighing scale (Mettler Toledo) followed by immersion into a beaker with $10 \mathrm{ml}$ of chloroform (100\%, GENE chemical). It was then weighed again and the weight difference before and after immersion was calculated.

The sealers were mixed according to each manufacturer's instructions and introduced into ten stainless steel rings. Ten rings were allocated each for $\mathrm{AH} 26$, Endofill and Sealapax. Two microscopic glass slides (Hirschmann Laborgerate $24 \mathrm{~mm} \times 24 \mathrm{~mm}$ ) were used at the top and bottom of each ring to produce flat surfaces.

The rings were then placed in a container with separate compartments labeled 'Ring 1' to 'Ring 10'. The container was placed inside an incubator (Memmert) with a temperature of $37^{\circ} \mathrm{C}$ for 48 hours to allow complete setting of the materials. After 48 hours, the microscopic glass slides were removed and any excess material surrounding the stainless-steel rings were removed and cleaned using a scalpel blade and tissue papers. Then, each ring was weighed in grams up to three decimal places using a digital weighing scale to obtain their initial weight. The rings together with the sealers were immersed into $10 \mathrm{ml}$ of chloroform for one minute in separate beakers. They were then blotted dry with absorbent papers and were placed again in the incubators at $37^{\circ} \mathrm{C}$ for 24 hours.

After 24 hours, each stainless-steel ring was weighed again using the same weighing scale for the final weight. The difference between the initial and final weight indicated the loss of sealer after immersion into the chloroform. The ten stainless steel rings were cleaned with acetone and they were re-used with the same procedures repeated for the other sealers. In addition, for the calcium hydroxide-based sealer, damp gauzes were used to wrap the rings containing the sealer. The results were collected and recorded into a Microsoft Excel spreadsheet. The data was analyzed using SPSS version 16.0. One way analysis of variance (ANOVA) was used to determine if there are any significant differences existed between the groups. Statistical significance was determined at $\mathrm{P}<0.05$.

\section{Results}

The results of this study were collected and analysed using one way ANOVA. The result of the ANOVA with a p-value of 0.029 indicates a significant difference of weight changes of the sealers after immersion into chloroform.

Table 1. ANOVA result

\begin{tabular}{llll}
\hline & Mean Square & F & Sig. \\
\hline Between Groups & 10.367 & 4.056 & .029 \\
Within Groups & 2.556 & & \\
Total & & & \\
\hline
\end{tabular}

Table 2. Comparison of weight changes between each sealer

\begin{tabular}{lllll}
\hline \multirow{2}{*}{ Reagent (I) } & Reagent(J) & $\begin{array}{l}\text { Mean } \\
\text { Difference(I-J) Std. Error }\end{array}$ & Sig. \\
\hline \multirow{2}{*}{ AH26 } & Endophill & .09259 & .73461 & 1.000 \\
& & & & \\
& Sealapex & 1.82593 & .73461 & .050 \\
Endofill & AH26 & -.09259 & .73461 & 1.000 \\
& & & & \\
& Sealapex & 1.73333 & .71501 & .068 \\
& AH26 & -1.82593 & .73461 & .050 \\
& Endophill & -1.73333 & .71501 & .068 \\
\hline
\end{tabular}

Table 2.0 showed multiple comparisons of differences in weight between the three sealers. The post-hoc test showed that AH 26 group reported significantly higher dissolution than Sealapex group $(\mathrm{P} \leq 0.05)$. There was no significant difference between weight changes of AH26 and Endofill and between Endofill and Sealapex. 
There were no changes in weight of the empty stainless steel rings after immersion in chloroform, showing that there was no dissolution effect of chloroform on them.



Figure 1. Line graph showing mean difference in weight

Figure 1.0 shows the mean differences in weight of the three endodontic sealers before and after immersion in chloroform. The graph shows AH26 possesses the highest mean value among all while Sealapax has the lowest mean.

Table 3. Median Test

\begin{tabular}{lllll}
\hline & & \multicolumn{3}{c}{ Reagent } \\
\hline & & AH26 & Endofill & Sealapex \\
Different weight in & $>$ Median & 5 & 6 & 3 \\
micro gram & $\leq$ Median & 4 & 4 & 7 \\
\hline
\end{tabular}

Table 3.0 shows no significant results in the median test (non-parametric) of the three sealers.

\section{Discussion}

Clinically, retreatment is done by mechanical means to remove all of the obturation materials and sealers. Sole use of mechanical means can lead to various problems including root perforation, canal straightening and alteration of the root canals' original shapes. Using chemical means as an adjunct to remove both gutta percha and sealers will minimize the risks of the above complications.

Chemical means in retreatment entail using chemical solvents to dissolve both gutta percha and sealers. Choloroform was chosen as the chemical solvent because it is the most effective and widely used solvent during retreatment. ${ }^{4}$ On top of that, chloroform has been widely used since 1850 as a gutta percha solvent. However, over the last 15 years, the use of chloroform has been negatively viewed due to the prohibition of its use by the Food and Drug Administration (FDA) in all drug and cosmetic product formulations.

As a matter of fact, chloroform exerted no negative health effects to dentists, dental assistants or patients..$^{5}$ With careful and controlled use, chloroform can be useful in the practice of dentistry. Even though chloroform was thought to have high carcinogenicity, the International Agency for
Research on Cancer (IARC) recently reported that the evidence of its carcinogenicity in humans is inadequate.

The success of the root canal treatment is partly determined by having a sufficient coronal and apical seal that is mainly contributed by the use of endodontic sealers. Thus, endodontic sealers are used to fill any voids or discrepancies between the gutta percha cones and dentinal walls. Apart from that, sealer is important in establishing a fluid tight or hermetic seal throughout the canal including apical foramen and canal irregularities. ${ }^{6}$

There are many classifications of sealers available; for example, polyketone, glass ionomer, zinc oxide eugenol, epoxy resin, calcium hydroxide, methacrylate resins, mineral trioxide aggregate and silicone based sealers. Among these, we have chosen three sealers which are, epoxy resin-based (AH26), zinc oxide sealer (Endofill) and calcium hydroxide (Sealapax).

Based on the experiment, ANOVA test showed significant difference in weight changes between all three sealers by a p-value of $0.029(\mathrm{p} \leq 0.05)$. This is statistically significant to reject the null hypothesis. The three sealers exhibit different dissolving effects towards chloroform.

On the other hand, Bonferroni test only showed a significant difference in the dissolving effect between AH26 and Sealapax towards chloroform. AH26 has a higher dissolving effect in chloroform compared to Sealapax. Meanwhile, when comparing AH26 and Endofill group and Endofill and Sealapax group, there were no significant differences between their weight changes. The dissolving effects of Sealapax towards the chloroform were affected due to its longer setting time compared to AH26 and Endofill. The setting reactions of calcium hydroxide-based sealers are complex because even if its outer surface becomes hard, the inner mass may remain soft in an extended period. ${ }^{8}$

In this study, the stainless-steel rings were used instead of extracted tooth because it would be difficult to obtain a standardized root canal length and diameter. Furthermore, the stainless-steel rings are stable and they are not affected by the dissolving effect of the chloroform. These factors make the relative weight changes absolute. This was proven in the control group which showed no changes in weight before and after immersion in the chloroform. All sealers were analyzed by using 10 specimens each, except for $\mathrm{AH} 26$ - only 9 specimens were used. One ring from the AH26 group gave no difference in weight change before and after immersion in the chloroform. This is due to some procedural errors during the experiment. That was the reason why the ring yielded no weight changes and it needs to be excluded from data analysis.

Nevertheless, it was found that calcium hydroxide basedsealer which is Sealapax took the longest time to set which is concurrent with one reported. ${ }^{3.9}$ that calcium hydroxide-based sealer did not set in capillary tubes and only set at clinical condition. 
Additionally, on the mean difference in weight, $\mathrm{AH} 26$ showed the highest mean difference in weight changes which indicate it dissolved better in the chloroform compared with the other two sealers. This result shows similarity to another report 10 that stated among all sealers used in the study, only AH26 dissolved in chloroform. Furthermore, Epoxy resin was the most soluble sealer when tested with chloroform whereas, calcium hydroxidebased sealer and zinc oxide eugenol-based sealer showed a higher solubility index towards eucalyptos oil. ${ }^{11}$ On the other hand, Endofill showed less dissolving effect in chloroform compared to AH26 where Endofill dissolves better in orange oil. ${ }^{12}$ The result of dissolution of Sealapax was the least among the three endodontic sealers used in this experiment as it did not attain its complete setting period. The result also showed similarity with another report9 that stated Sealapax has no dissolution effect on chloroform. Furthermore, Sealapax showed high significant weight loss after 14 days of exposure towards saliva and water whereas, $\mathrm{AH} 26$ showed the lowest. ${ }^{13}$

\section{Conclusion}

Within this limit of in vitro investigation, it can be concluded that AH26, Endofill and Sealapax have dissolution effect towards chloroform, being AH26 dissolve the best in chloroform. The results of this study meet the aims and the objectives which were to evaluate the dissolving effect of endodontic sealers towards the chloroform.

For future in vitro study of the same aims and objectives, it is suggested that the sample size is to be increased to obtain a more accurate data analysis. Furthermore, for calcium hydroxide-based sealer, it is suggested that another in vitro study needs to be carried out to find a suitable solvent.

\section{Acknowledgment}

We would like to acknowledge and thank the following people which are our beloved research supervisor, Asst Prof Dr Kyaw Mya Htun for providing us with knowledge, guidances, advices, budgets and continuous support and serving on our research project and also the research committees consisting of Assoc Prof Khairani Idah Mokhtar, Assoc Prof Dr Solachudin Ichwan, Dr Pram Kumar Subramaniam and sub-committees for always supporting and making sure we are on the right tract.

\section{References}

1. Burleson WL, Bagby MD, Jackson CR, Razmus TF. Solubility of Endodontic Sealers in Three Common Endodontic Solvents. Department of Endodontics Morgantown; 2008.

2. Torabinejad M, Ung B, Kettering JD. In vitro bacterial penetration of coronally unsealed endodontically treated teeth. J Endod 1990;16(12):566-569

3. Erdemir A, Adanir N, Belli S. In Vitro Evaluation of the Dissolving Effect of Solvents on Root Canal Sealers. J Oral Sc. 2003: 45(3):123-126
4. Martos J, Silveira LF. Use of Organic Solvent in Endodontics: A Review. Clin. Psq. Odontol 2006; 2:393399

5. McDonalds MN, Vire DE. Chloroform in The Endodontic Operatory. J Endodon 1992; 18: 301-303

6. Zheoul HM, Shen Y, Zheng W, Li Li, Zheng YF, Haapasalo M. Physical Properties of Five Root Canal Sealers. J Endodon $2013 ; 39: 1281-1286$

7. Ingle JI. Endodontics. 6th ed. Philadelphia: Lea \& Febiger 1985.(1034-1043)

8. Desai S, Chandler N. Calcium Hydroxide-based Root Canal Sealers; A Review.J Endodon 2009; 35:475-480

9. Hansen MG. Relative Efficiency of Solvents Used in Endodontics. J Endodon 1998; 24: 38-40

10. Mushtaq M, Masoodi A, Faroouq R, Khan FY. The Dissolving Ability of Different Organic Solvents on Three Different Root Canal Sealers: In Vitro Study. Iranian. Endod J. 2012: 7(4):198-202

11. Schafer E, Zandbiglari T. A Comparison of Effectiveness of Chloroform and Eucalyptos Oil in Dissolving Root Canal Sealers. J Oral Med Oral Path Oral Rad, Endodon 2002 ; 93: 611-616

12. Martos J, Silveira LF, Silveira CF, De Castro LA, FerreLuque CM. The Effect of Different Organic Solvents on The Degradation od Restorative Materials. European J of Dentistry 2013; 7:347-351

13. Schafer E, Zandbiglari T. Solubility of Root Canal Sealer in Water and Artificial Saliva. Int Endodon J 2003; 26: 660669 